when racking billiard balls - and place another layer on top, and repeat. There are two ways to place subsequent layers. Viewed from above, there are three different positions for the centres of the spheres in any one layer, say A, B and C. If the layers follow the order A, B, C, A, B, C, ..., then the f.c.c. packing is obtained. If they follow the order $\mathrm{A}, \mathrm{B}, \mathrm{A}, \mathrm{B}, \mathrm{A}, \mathrm{B}, \ldots$, then an equally dense packing known as the hexagonal close packing (h.c.p.) is obtained.

Kepler's conjecture is that there are no packings that are denser than the f.c.c. or the h.c.p. packings (or any one of the infinite number of different packings obtained by varying the order of the layers). The f.c.c. and h.c.p. packings have the same density, but they are different: one is a lattice, the other is not. Spiro claims that the f.c.c. and the h.c.p. are "the exact same packing, viewed from different angles". They are not.

Another distraction in the mathematical discussions (which fortunately are set in a different typeface, so they can - and should - be skipped by the casual reader) is the author's misuse of the word 'surface'. Several times he writes of the surface of an object, when he means its area, or even its volume.

One of the oldest theorems about sphere packing was proved by Gauss in 1831, when he showed that the f.c.c. is the densest lattice packing of spheres. Szpiro attempts to reproduce Gauss's proof, but makes a mess of it. For example, on page 255 the determinant needs to be negated, and denoted by a new symbol, $\Delta$, say. Then six occurrences of the letter $D$ on that page need to be changed to $\Delta$. Similar repairs are needed on the next page.

The book hardly mentions one of the main reasons for studying the packing of spheres: its application to digital communications. From the communication theorist's viewpoint, Hales' result on three-dimensional sphere packing is just the beginning of the story. One of the fundamental questions in communication theory is to determine the densest packing of equal balls in multidimensional space. A geometrical way of representing signals, which is at the heart of Claude Shannon's mathematical theory of communication, underlies the high-speed modems that we now take for granted.

Szpiro mentions this subject only briefly, in the final chapter, but the discussion is marred by another error. He describes the following problem as a far-fetched application of packing problems (it is actually a standard type of problem in error-correcting codes). The problem is to find as many strings of ten decimal digits as possible, subject to the constraint that any two of the strings must differ by at least two units in each position. He misuses the known bounds on the density of sphere packing in ten-dimensional space to conclude that "at least $400,000,000$ signals can be represented, which is sufficient for all words in all languages of the globe". However, the correct answer is not 400,000,000, but 5 .

One can only admire Szpiro's valiant attempts to explain the different approaches used by Richard Buckminster Fuller, Wu-Yi Hsiang and Hales in their attacks on the problem (although the serious reader would do better to read Hales' own descriptions). Szpiro's discussion of the arguments between the protagonists is certainly entertaining. He illustrates them with a quotation from Henry Kissinger, who "was once asked why departmental fights are so violent, why back-stabbing is so common among academic colleagues. His answer was short and to the point: 'Because the stakes are so small'" Typically, not quite relevant, but a good story.

As long as readers skip over the technical sections, the book can be recommended as a readable and informative account of a fascinating chapter in the history of geometry.

Neil Sloane is at the AT\&T Shannon Laboratory, 180 Park Avenue, Florham Park, New Jersey 07932-0971, USA.

\section{The rise and fall of the Universe}

\section{Alpha and Omega: The Search for the Beginning and the End of the Universe}

by Charles Seife

Viking Press: 2003.304 pp. $\$ 24.99$

Doubleday: 2003. $£ 18.99$

\section{Peter Coles}

The potentially lucrative market for popular cosmology is pretty crowded these days, so if a book is to be successful it has to stand out from its competitors. One strategy for a publisher is to sign up a professional scientist with something special to say. João Magueijo's Faster Than the Speed of Light (reviewed in Nature 422, 563-564; 2003) and Janna Levin's How the Universe Got its Spots (Weidenfeld $\&$ Nicolson/Princeton University Press, 2002) are two recent books, both written in distinctive, even quirky, styles by specialists for a lay audience. Although very

The collision of gold nuclei at almost the speed of light creates particles in conditions like those just after the Big Bang. different, these books have much in common. Both are insiders' views of the subject, both are highly original because the subject matter is seen from the perspective of the authors' own research, and both include a lot of autobiographical material.

Few scientists are capable of putting their understanding and experiences into words as effectively as these two, so publishers have instead enlisted professional writers to look at the subject from the outside. A science journalist may not have as deep an understanding of the technicalities as a research scientist, but may be more experienced at writing for the general public and consequently better at getting the basic ideas across. Particularly successful examples of this genre are The Whole Shebang by Timothy Ferris (Weidenfeld \& Nicolson/Simon \& Schuster, 1997) and, more recently, Bill Bryson's A Short History of Nearly Everything (reviewed in Nature 424, 725; 2003), which both demonstrate that winners need not necessarily be on the inside track. Sadly, Alpha and Omega by Charles Seife is not among the medal positions.

The book starts promisingly enough, if you can forgive the pseudo-religious overtones of the title (a reference to the Book of Revelations). The suggested emphasis on both the beginning and the end seems a good idea, as there are many books about the birth of the Universe but relatively few about its death. Unfortunately, despite the claims made on the jacket, this theme isn't really taken up by the book itself, except for a few comments in the final chapter. 
Instead we have a fairly conventional account of the historical development of cosmology from antiquity to modern times. This account is up-to-date, including such developments as the preliminary release of data from the Wilkinson Microwave Anisotropy Probe and the latest observations of distant supernovae, and is accompanied by some nice illustrations. It is, for the most part, quite well written, but there is too much repetition, some of the diagrams are incomprehensible, and the text is peppered with unnecessary and distracting footnotes.

There may be a place for footnotes in a scholarly monograph, but in a popular book they are usually signs of sloppy writing. If they say something important they should be incorporated into the text, otherwise the casual reader may miss something vital. If they are not essential, they should be left out for fear of muddying the water.

An example from this book relates to Arthur Eddington's eclipse expedition of 1919 to the West African island of Principe, where he made the first measurement of the deflection of light by the Sun, predicted by Einstein's general theory of relativity. Afterwards, Eddington wrote a poem containing the phrase "light has weight". In a footnote, Seife claims that this is misleading because light "does not actually have mass". In everyday language, mass and weight are moreor-less synonymous, but any high-school physics student knows that these terms have quite different meanings in the language of classical mechanics. Eddington knew the difference too. In newtonian language, weight is a measure of the gravitational force on a body. A massive body can be weightless, if it is in freefall or in a region without a gravitational field. On the other hand, in Einstein's theory, massless particles such as photons can feel the effects of gravity, so it is reasonable to describe them as having weight. No poetic licence is required, and I'm not sure Eddington possessed one anyway.

This may seem a pedantic objection, but my grumble is less about the fine distinction between the concepts of weight and mass as about the pointlessness of raising the issue in the first place. Besides, errors of fact are even less forgiveable than errors of judgement: the famous eclipse mentioned above happened on 29 May 1919, not 26 March, as stated by Seife.

I can offer a useful general tip about popular- science books: stop reading immediately when you come across the word 'mindboggling. This is the point where the author admits defeat, so it's only fair for the reader to do likewise. Applying that principle to this book will get you about half-way or, on a scale from alpha to omega, about as far as mu.

Peter Coles is in the School of Physics and Astronomy, University of Nottingham, University Park, Nottingham NG9 2HL, UK. He is the author of Cosmology: A Very Short Introduction.

\section{Pixels and piety}

\section{The digital collection at the Museum of the History of Science in Florence.}

\section{Martin Kemp}

Many museums have spent large sums of money embracing the digital age, often to no great effect.

Online access to images and information is certainly valuable in extending the audience of any museum, but most of the projects go no further than archiving, and make little creative use of the potential of digital imaging. Likewise, most of the on-site digital access that museums provide for their visitors relies on low-level interactivity conceived by middle-aged curators who hope that touching a computer screen will transform the museum experience for 'young people'.

Happily, a few museums are now moving on to a more creative level to enhance their interaction with both real and virtual visitors. No museum has a more ambitious programme in this respect than the Museum of the History of Science in Florence, Italy, whose director, Paolo Galluzzi, is developing an imaginative range of digital access (as the site map at galileo.imss.firenze.it testifies). The most ambitious of the projects, Galileo//thek@, will, when it is completed in February 2004, provide the most comprehensive set of images, primary sources, interpretative materials and animations for any historical figure. Animations, of which there are several on the museum's website, are particularly important, as they provide an immediate and dynamic insight into the working of instruments that sit as inertly as sports trophies in their sealed museum cabinets.

In Florence, the latest technologies are blended with extraordinary levels of traditional reverence for Galileo, the 'god' of Tuscan science. Alongside hard-nosed information about galilean astronomy and dynamics, scholarly information about manuscripts and editions, and extensive secondary literature, are some extraordinary memorabilia of the Italian scientist, presented with a piety that is at least the equal of any found in a church. The most sanctified relic is the shrivelled middle digit of Galileo's right hand - the medium of which is laconically listed in the museum catalogue as "finger"!

When Galileo's remains were transferred to the main body of the Florentine church of Santa Croce on 12 March 1737, the antiquarian, Anton Francesco Gori, took the opportunity to detach the finger as if it were a revered fragment from the corpse of a saint. For many years, the relic was exhibited in the Biblioteca Laurenziana, having acquired its elaborate eighteenth-century mount and inscription, before passing in 1841 to the new Tribuna di Galileo in the Museo di Fisica e Storia Naturale on the via Romana in Florence, and eventually to its current resting place.

The flavour of such piety is embodied in another Galileo reliquary now housed in the same museum. This contains the objective lens used by the astronomer in 1610 to discover the moons of Jupiter, which he designated the 'Medicean Planets'. Mounted in a florid ivory frame by Vittorio Croster in 1677, it was for years part of the cherished collections of the Medicean Grand Dukes of Tuscany in the Galleria degli Uffizi, alongside the masterpieces of Leonardo, Michelangelo and Raphael. 